\title{
Studies of Optical Properties of Protonated Polyazomethine Thin Films
}

\author{
H. Bednarski ${ }^{a, *}$, J. Weszka ${ }^{a}$, M. Domański ${ }^{a}$ And V. COZAn $^{b}$ \\ ${ }^{a}$ Centre of Polymer and Carbon Materials, Polish Academy of Sciences \\ M. Curie-Skłodowskiej 34, 41-819 Zabrze, Poland \\ ${ }^{b}$ Petru Poni Institute of Macromolecular Chemistry, Aleea Gr. Ghica Voda 41 A, 700487 Iasi, Romania \\ We report results of experimental studies supplemented with the first principles calculations aimed to explain \\ influence of doping on electronic and optoelectronic properties of thin PPI films. It has been predicted theoretically \\ and confirmed experimentally that chemical doping with the $\mathrm{HCl}$ acid vapor is thermally reversible process due \\ to relatively low energy barrier for protonation.
}

PACS: 78.20.Ci, 78.20.Bh, 78.40.Me

\section{Introduction}

The poly ( $p$-phenyleneazomethine) (PPI) belongs to alternately conjugated polymers revealing semiconducting properties, thus belonging to the family of organic semiconductors. The architecture of the most conjugated polymers consists of chains of carbon atoms linked by alternate single and double bonds or alternate $\mathrm{C}=\mathrm{C}$ and $\mathrm{B}$ units, where $\mathrm{B}$ stands for the benzene (phenyl ring). This is the case for many prototypical conjugated polymers, such as polyacetylene, $\operatorname{poly}(p$-phenylene) and $\operatorname{poly}(p$-phenylene-vinylene $)$. Since the $-\mathrm{N}-\mathrm{B}-\mathrm{N}=\mathrm{C}-$ $\mathrm{B}-\mathrm{C}-$ group is isoelectronic with the $-\mathrm{C}-\mathrm{B}-\mathrm{C}=\mathrm{C}-\mathrm{B}-$ $\mathrm{C}-$ group, the incorporation of nitrogen atoms into the conjugated system leads to another class of conjugated polymers closely related to poly ( $p$-phenylene vinylene)s, namely polyazomethines poly(aromatic-Schiff bases) and polyketanils (polyketimines) [1-5]. Conjugated polyketanils can be considered as simple derivatives of the corresponding polyazomethines in which the hydrogen atom of the azomethine group is replaced by an aryl or alkyl group.

Doping of conjugated polymers is a well established way of influencing on important electronic, optoelectronic and mechanical properties of semiconducting polymers. Doping of polyazomethines is realized mainly by acid base chemistry [1], which makes the process complex and difficult to control.

The purpose of this work is to study optical properties of protonated PPI thin films and begin on theoretical studies on protonation mechanism of this group of materials, emphasis being put on a role of the counter ion. Our

\footnotetext{
* corresponding author; e-mail: hbednarski@cmpw-pan.edu.pl
}

first-principles studies are aimed to explain influence of doping on electronic and optoelectronic properties of thin PPI films. Theoretical studies carried out on aromatic-Schiff bases have so far focused on elucidation of the ground-state conformation of the trans- $N$-benzylideneaniline [6-8], studies of electronic structures of PPI [2].

\section{PPI thin films preparation, protonation and experimental details}

Thin films of PPI have been prepared by chemical vapor deposition (CVD) method based on condensation polymerization between $p$-phenylene diamine (PPDA) and terephthalaldehyde (TPA) monomers with gaseous argon used as a transport agent as it was discussed [3]. The as-prepared PPI thin films were examined with the $\mathrm{UV}-\mathrm{V}$ is spectrophotometer, and then, they were put into $\mathrm{HCl}$ vapor action to protonate them.

\section{Results}

UV-Vis spectra recorded on pristine and $\mathrm{HCl}$ protonated PPI thin films are presented in Fig. 1. Two characteristic experimental features clearly visible upon protonation are a red shift of the maximum of main absorption band and disappearance of relatively weak absorption band centered at $\lambda=300 \mathrm{~nm}$. Additionally, thermal reversibility of protonation process is documented. To reveal microscopic processes responsible for observed changes in the optical spectra the mechanism of protonation of PPI chain is analyzed first.

The characteristic feature of the PPI chain structure is the periodically repeated sequence of $\mathrm{CH}=\mathrm{N}$ bonds joint with the benzene rings as presented in Fig. 2. It seems to be quite reasonable to begin the theoretical analysis of 


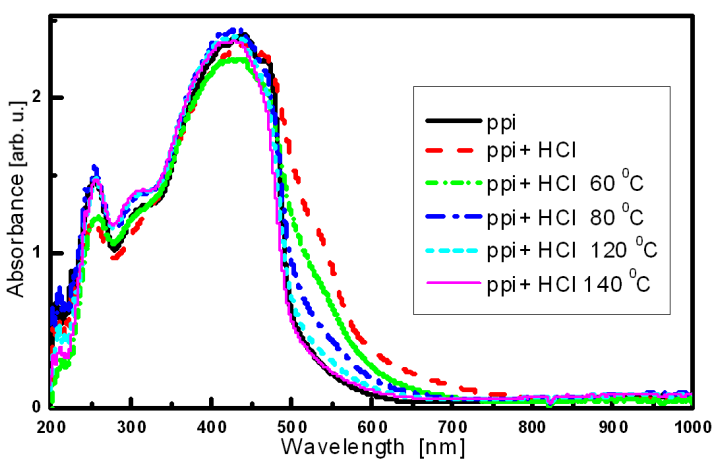

Fig. 1. Experimental UV-Vis spectra of $\mathrm{HCl}$ protonated PPI thin films and annealed at indicated temperatures.

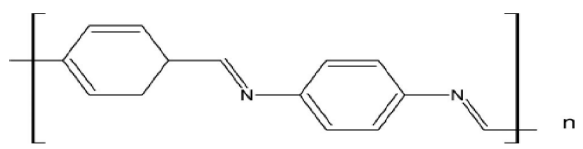

Fig. 2. A fragment of PPI polymer chain.

microscopic mechanism of protonation by considering the simplest model, which possesses the main molecular root of PPI. It appears that the trans- $N$-benzylideneaniline (tBA) molecule with the hydrochloric acid molecule as a protonating agent is a suitable candidate for that purpose, as it can be considered as a part of PPI unit cell. For this model, the first-principles calculations are carried out within the density field theory (DFT) and the B3LYP [9] exchange correlation functionals using 6-31G(p,d) basis set [10]. All reported here calculations have been performed using the GAUSSIAN 03 computer program [11]. In particular, the optimized scans of the potential energy surface (PES), with respect to the tBA imine and $\mathrm{HCl}$ hydrogen distance $d(d-$ scan coordinate) have been calculated.

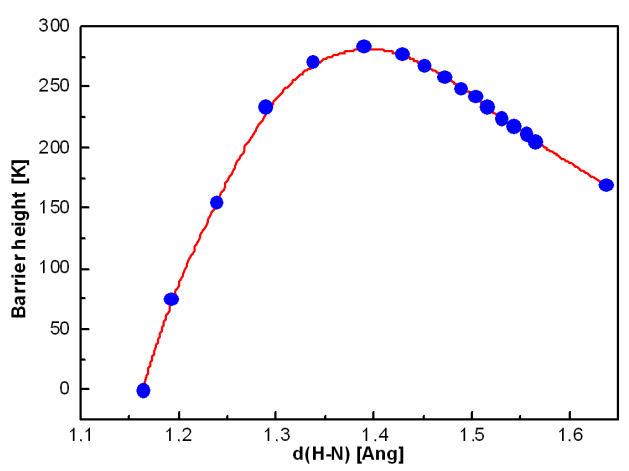

Fig. 3. The barrier height for protonation as a function of hydrogen distance $d$, for the model described in the text.

Results are presented in Fig. 3 and may be summarized as follows. $\mathrm{HCl}$ molecule can approach the nitrogen atom up to distance $d=1.64 \AA$, the first local minimum of the PES. At this stage no covalent bonds are broken or formed. The next minimum of the PES at $d=1.16 \AA$ is however separated by $\Delta E=275 \mathrm{~K}$ high energy barrier. At this stage the $\mathrm{H}-\mathrm{Cl}$ bond is broken and $\mathrm{H}-\mathrm{N}$ covalent bond is formed.

Our results have revealed that the barrier height for protonation tBA with the hydrochloric acid molecule is quite low, thus one can conclude that protonation of tBA should be thermally reversible process. Assuming application the same mechanism to PPI thin films protonation one should expect that thermal annealing of protonated thin PPI films will lead to de-protonation. This is indeed what we observed experimentally for the thin PPI films exposed very shortly on the acid vapor, see Fig. 1. Longer exposure on $\mathrm{HCl}$ vapor resulted in protonated films resistant to thermal annealing, however presence of unwanted degradation reactions should be carefully analyzed. These important issues concerned with thermal stability of protonated PPI thin films are currently under investigations and beyond scope of this work. We note only that the very simple model we used here to investigate protonation mechanism of PPI thin films is aimed to elucidate the basic molecular features of this process.

Having gained basic understanding on protonation mechanism of PPI thin films by acid base chemistry one can analyze the influence of PPI chain protonation on its electronic structure. It appears that electronic structure of the PPI chain is strongly related to its conformation. Namely, as it was reported by us previously, see Ref. [2], conformation of PPI chain is not planar, torsion angles between two adjacent phenyl rings in PPI chain equals $34^{\circ}$. Basing on results on protonated tBA [7] one can also state that this nonplanarity is caused by couplings of nitrogen atoms lone pair of electrons with $\pi$ electrons of the nearest phenylene ring, which weakens conjugation within $\pi$ electrons along the chain. As protonation involves the nitrogen lone pair of electrons, it enhances conjugation within $\pi$ electron system. Therefore, one can expect that protonation would leads also to planarization of PPI chain. Indeed, as follows from our calculations performed for PPI chain, carried out imposing the periodic boundary condition on the repeated monomer unit, the corresponding torsion angle decreases by about $6^{\circ}$.

We proceed now to interpreting reported here UV spectra of protonated PPI thin films. For this purpose we have calculated and compared the UV spectra of neutral and protonated slightly larger model molecule, namely corresponding to two monomer units. Calculated spectra are presented in Fig. 4. Two main features can be observed from comparison, a red shift of the maximum absorption band and disappearance of the relatively weak peak centered at $290 \mathrm{~nm}$. There are the same features as revealed from experimental data in Fig. 1. Therefore, our analysis clarified the origin of observed changes in UV spectra upon protonation as coming from molecular rearrangement. 


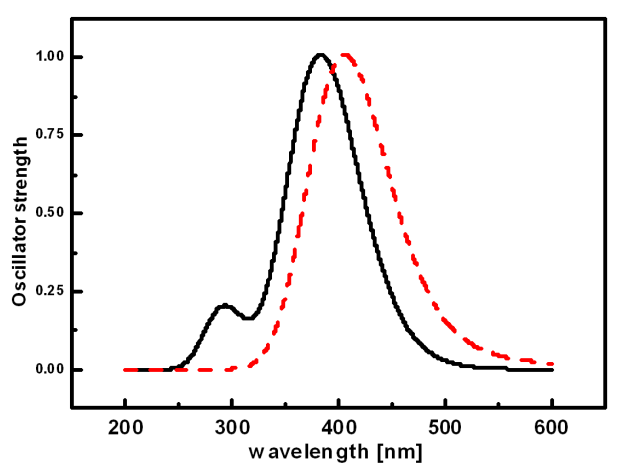

Fig. 4. Comparison of calculated UV-Vis spectra for the pristine (solid line) and protonated model (dotted line) of PPI.

\section{Acknowledgments}

The project financed from means of the National Science Centre no. N N508626840.

\section{References}

[1] A. Iwan, D. Sek, Prog. Polym. Sci. 33, 289 (2008).

[2] J. Weszka, H. Bednarski, M. Domanski, J. Chem. Phys. 131, 024901 (2009).

[3] J. Weszka, M. Domanski, B. Jarzabek, J. Jurusik, J. Cisowski, A. Burian, Thin Solid Films 516, 3098 (2008).

[4] S. Gunes, H. Neugebauer, N.S. Sariciftci, Chem. Rev. 107, 1324 (2007).

[5] S.-S. Sun, N.S. Sariciftci, Organic Photovoltaics: Mechanisms, Materials and Devices, Taylor\&Francis Group, Broken Sound Parkway (NW) 2005.
[6] H. Xu, K. Sohlberg, Y. Wie, J. Mol. Struct. (Teochem) 634, 311 (2003).

[7] H. Bednarski, M. Domański, J. Weszka, K. Sohlberg, J. Mol. Struct. (Teochem) 908, 122 (2009).

[8] D. Sek, A. Iwan, B. Kaczmarek, J. Kasperczyk, H. Bednarski, High Performance Polymers 19, 401 (2007).

[9] M. Frisch, G.W. Trucks, H.B. Schlegel, G.E. Scuseria, M.A. Robb, J.R. Cheeseman, J.A. Montgomery, T. Verven Jr., K.N. Kudin, J.C. Burant, J.M. Millam, S.S. Iyengar, J. Tomasi, V. Barone, B. Mennucci, M. Cossi, G. Scalmani, N. Rega, G.A. Petersson, H. Nakatsuji, M. Hada, M. Ehara, K. Toyota, R. Fukuda, J. Hasegawa, M. Ishida, T. Nakajima, Y. Honda, O. Kitao, H. Nakai, M. Klene, X. Li, J.E. Knox, H.P. Hratchian, V. Cross, J.B. Bakken C. Adamo, J. Jaramillo, R. Gomperts, R.E. Stratmann, O. Yazyev, A.J. Austin, R. Cammi, C. Pomelli, J.W. Ochterski, P.Y. Ayala, K. Morokuma, G.A. Voth, P. Salvador, J.J. Dannenberg, G. Zakrzewski, S. Dapprich, A.D. Daniels, M.C. Strain, O. Farkas, D.K. Malick, A.D. Rabuck, K. Raghavachari, J.B. Foresman, J.V. Ortiz, Q. Cui, A.G. Baboul, S. Clifford, J. Cioslowski, B.B. Stefanov, G. Liu, A. Liashenko, P. Piskorz, I. Komaromi, R.L. Martin, D.J. Fox, T. Keith, M.A. AlLaham, C.Y. Peng, A. Nanayakkara, M. Challacombe, P.M.W. Gill, B. Johnson, W. Chen, M.W. Wong, C. Gonzalez, J.A. Pople, Gaussian 03, Revision E.01; Gaussian, Inc., Wallingford, CT 2004.

[10] A.D. Becke, J. Chem. Phys. 98, 5648 (1993).

[11] P.J. Stephens, F.J. Devlin, C.F. Chabalowski, M.J. Frisch, J. Phys. Chem. 98, 11623 (1994). 